\title{
Digital and Conventional Microscopy - Learning Effects Detected through Eye Tracking and the Use of Interactive Whiteboards
}

\author{
Julia Berg ${ }^{1}$, Lissy Jäkel ${ }^{1, *}$, Anamarija Penzes ${ }^{2}$ \\ ${ }^{1}$ Institute for Natural Sciences, Geography, and Technology, University of Education, Germany \\ ${ }^{2}$ Department of Media Studies, Faculty of Cultural Sciences and Humanities, University of Education, Germany
}

Copyright $\bigcirc 2016$ by authors, all rights reserved. Authors agree that this article remains permanently open access under the terms of the Creative Commons Attribution License 4.0 International License

\begin{abstract}
Learning the meaningful use of the microscope is an essential requirement in school curricula. Modern science and medicine is hardly conceivable without the inclusion of microscopy. The number of didactic studies in this area, however, is negligible. Real microscopy is rarely used to gain knowledge in higher school years. Could the understanding of cell concept and the skills to interpret histological structures be complemented and supported by digital microscopy? The current study investigates this problem in two methodological ways. First, learning effects of modules with interactive whiteboards (IWB) are compared with original microscopy (2012: $n=70 ; 2013$ : $25+14 ; 2013 / 14: \mathrm{n}=21+27 ; 2014: \mathrm{n}=40$ ) using the example of human biology with pre-service student teachers. The instruments were questionnaires (short scale of intrinsic motivation, flow, and knowledge test) and interviews. Second, eye movements of 12 th grade students were measured during histological image processing of retina and nervous tissue in the student laboratory of neuroscience in Tubingen (High Quality Tower mounted eye tracking) (2013: $n=11+26 ; 2014: n=28$ ). We measured that fixation in the area of interest (AoI) corresponded with the level of prior knowledge. The estimation of instructional aids (e.g. schematic representation) while viewing demanding histological images also depends on prior knowledge. The same applies to the IWB. The use of the whiteboard is valued because of the possibility to make visible connections and put these in contexts. The use of the whiteboard does not, however, surpass the motivation and flow of real microscopy in problem-oriented learning processes. The IWB is a good supplement but is not a substitute for the microscope.
\end{abstract}

Keywords Microscopy, Eye Tracking, Interactive Whiteboard, Retina

\section{Introduction}

Cells are the basic structure of all living things. It is essential to grasp the concept of cells to comprehend the relationships between structures and functions of living things. Thus, microscopy is an important skill with which to acquire knowledge for a basic understanding of biology.

We would like to better understand why more both mature students and pre-service teachers have difficulties working with the microscope and which observation patterns they show. This seems necessary to develop meaningful didactic measures to improve microscopy at school. Among other things, we would like to examine in how far we can adapt digital histological images for school purposes. Are colored schematic images, as commonly used in text books or other learning material, sufficient to understand cellular structures of the retina or other basic histological structures?

Somewhat older media studies show contradictory findings on the use of images. Line illustrations or schematic images may cognitively be more effective than real images because they don't distract the observer through details [1]. Microscopic images, however, are highly complex and can overwhelm inexperienced observers. On the other hand, images may act as affective stimuli. They attract attention and motivate for further learning activities. Learners evaluate realistic pictures as being interesting and motivating [2].

In life sciences and medicine, microscopy is making huge developments and is indispensable. Learning the meaningful use of the microscope is an essential requirement of school curricula connected with grasping the Nature of Science (NOS). Working with the microscope must not only be seen as a technical part of lab work but also as another demanding skill of gaining knowledge in biology. Our model of development of competencies [3] in terms of working with the microscope contains the following steps: 
level 1- basic practical knowledge of the use of the microscope;

level 2 - conviction of the usefulness of the application of the microscope in different situations;

level 3 - use of the microscope specifically to clarify scientific phenomena (scientific reasoning);

level 4 - appropriate use of the microscope in biology is associated with a clear understanding of the cell concept of living beings (epistemological views)."

We were able to reveal how interest in microscopy can increase through problem-based learning [3].

The reasons for the scarcity of microscopy in connection with demanding content at schools may be, among others, inadequate technical equipment. Some histologists have very high expectations on digital microscopy. "The choice of a system for virtual microscopy should be made considering the central aspects of successful teaching and learning." [4]. These expectations, though, concern university histologists and anatomists more than school pupils.

We believe, however, that the competences of future teachers in conventional or digital microscopy are the essential prerequisites for active instructional implementation.

\section{Methodology of Research}

\subsection{General Background of Research}

\subsubsection{Further Research on Microscopy at School}

In Japan, a "microscopy-license" with 9 workshops was developed and researched on two groups of students [5]. ,As a whole, although the participants found the program difficult, they were satisfied because they were able to learn a variety of things and their interest in science was heightened."

School projects connected to microscopy, e.g. [5], in which physicians and cell biologists were to some extent involved, were not ultimately orientated towards technical skills but instead towards grasping the Nature of Science (NOS), e.g. [6].

Students in elementary biology classes are fascinated by microscopy. In higher classes, microscopy is hardly done. Microscopic drawing is frowned upon. School graduates are challenged by the complexity of concrete configurations and have little practice.

\subsubsection{Use of Digital Images in Histology}

The establishment of digitally supported microscopy began in medical studies, e.g. [7]. No significant difference in diagnostic accuracy could be detected between the diagnoses proffered on the basis of virtual slides and conventional slides, but using virtual slides took pathologists considerably longer [8].

Merk, Knuechel, and Perez-Bouza [4] report: "Three groups with a total of 192 students ... of medical studies attending the practical courses of general and advanced histopathology had access to both glass-mounted and digitalized slides. Prior to exams, students were asked to answer an anonymous questionnaire. The results of the study reflect the high acceptance and intensive use of the web-based digital histology by students ... of histology and pathology" [4]. "The combination of fast barrier-free transmission of the images with a self-explaining and didactic as well as optical attractive microscope" seems to be a challenge for students of medicine [4]. "This new way of labelling ... can be described as a "textbook within the histological picture." Precise feedback is necessary for the identification of relevant configurations.

Studies about digital microscopy at school and learning effects, however, are rare.

\subsubsection{Saccades and Fixations in Image Processing}

Conscious and subconscious decisions play a role in attentiveness and fixation of the fovea centralis when regarding images. Saccades occur between the fixations. Attentive processing is the conscious and targeted processing of images according to certain criteria. In pre-attentive processing, an image is intuitively processed as a whole, and no particular concentration is necessary. Both types of processing take place simultaneously.

The cognitive theory of multi-media study CTLM [9] from Mayer deals with the integrative processing of text and image. The closer verbal and visual information are, the more likely it is that both sources of information will be used. Thus, the principle of contiguity is valid. The spatial proximity of connected text/image information has proved to be an important variable of the instructional design of multi-media learning environments (split-attention effect). The Cognitive Load Theory [10] offers explanations to what extent the spatial proximity of multiple sources of information influences the cognitive burden of learners.

Eye movement studies in fine arts or media studies offer, e.g. [11] clues about the interaction between the text and the image, the user interface, and the role of prior knowledge. According to this, visual-spatial content, for example, is learned better close to the hands, and semantic content is learned better farther away from the hands [12]. Such aspects are essential for the choice of technical systems and the design of educational material (e.g. for the IWB) and further content-related research should be done. Sieve [13] refers to the fact that, despite around half of high schools being equipped with IWB, there is little reliable empirical research on the potentials of the boards for natural science education in the German-speaking region.

\subsubsection{Expertise Reversal Effect}

Sweller et al. [10] argued that instructional design can be used to reduce cognitive load for learners.

There are differing effects of externally provided instructional guidance on learners with varying levels of prior knowledge. If additional instructional guidance in situations with schema-based knowledge is provided to higher-knowledge learners, it can result in the processing of 
redundant information and increased cognitive load [14]. In contrast, low-knowledge learners lack schema-based knowledge in the target domain, so this guidance comes from instructional support, which helps reduce the cognitive load associated with novel tasks. "Instructional guidance, which may be essential for novices, may have negative consequences for more experienced learners" (Expertise Reversal Effect) [14].

According to the cognitive theory of multi-media studies, it is believed that learners engage actively with the learning material in order to construct a coherent mental representation of their previous experiences [9]. According to Moreno and Mayer's [5] similar cognitive-affective theory of learning with media, it is believed that motivational factors and learning strategies influence learning by raising or lowering the cognitive involvement of learners. Are these models also valid for different knowledge domains, though?

\subsubsection{Eye Tracking in Biology and Medicine}

Yarbus [16] conducted fundamental research on eye movements. Nowadays, eye movements can be accurately recorded using a computer, e.g. [17]. A scan path is documented. High quality eye movement studies are time-consuming because of the required exact calibration, while the sample sizes remain small. Precise scan paths, however, are a necessary resource for understanding both image processing and histological comprehension.

Visual expertise is of crucial importance for clinical pathologists.

Banzhaf et al. [18] found differences between novices and those experienced in dermoscopy recognizing Melanoma in histological images $(n=25)$. "Novices had a longer and more complex gaze track pattern".

Jaarsma et al. [19] compared pathologists ( $\mathrm{n}=13)$ residents (12) and medical students (13). They diagnosed 10 static, colored microscopic images in 2 seconds of viewing time. Intermediates seemed to check; experts explored. Results show that novices fixate less in Areas of Interest (AoI), often diagnose incorrectly, and are vague and incorrect in their explanations. The studies of eye movement showed, however, that histologists exhibit a more target-oriented scan path than novices.

\subsubsection{Flow and Multimedia Learning}

Experiencing flow is of particular concern because microscopy, as a process of recognition, is a sophisticated activity (compare with [5]). Rheinberg et al. [20] distinguished between demand and challenge of the activity. When working with histological images, the initially unaccustomed but required operation of the interactive whiteboard (IWB) is added to the complexity of the cellular configurations. Using such a whiteboard, the images can be manipulated, linked, or labeled using a pen or by hand. "A task that balances challenge and ability results in a challenge that is psychologically motivating" [20, p. 267]. Flow means "being completely wrapped up in a task that is running smoothly and that, despite strain, one still has under control.
This state is generally perceived as being pleasant" [20].

\subsubsection{Questions}

On the basis of the aim of the study, following research questions were determined:

- What do experts and novices gaze at when using a microscope or when processing a histological image?

- Is it possible to verify the stimulating effect of problem-centered work in eye movement recordings using histological images?

- Does the number of saccades or fixations, respectively, correspond with the expert status of students?

- For comprehension, is it helpful to combine schemata with histological images?

These questions were examined with the help of eye tracking.

But is it possible to compare searching cells and interpretation of histological structures while looking at histological images with real microscopy?

The IWB modules complement the eye tracking. A systematic comparison and reconciliation of the two techniques was carried out.

The Research question for this is the following:

- Does the IWB support necessary microscopy competences, such as the ability and willingness to specifically align histological images while acquiring insight and solving problems?

\subsection{Methods}

\subsubsection{Eye Tracking Methodology}

The study investigates histological image processing in two methodological ways. First: Eye tracking. Three measurement series were completed with the so called tower mounted eye tracker.

The tracking of eye movement patterns requires a special apparatus (Arrington Research USB220, frequency $220 \mathrm{~Hz}$, the spatial resolution is $0.01^{\circ}$ ). Students of higher secondary school were observed while examining histological images at a student laboratory of neuro science in Tuebingen, Germany. Tower-mounted high quality eye-tracking recordings (non-invasive infrared oculography) were done in August 2013 with 11 subjects (six males, five females) and with 26 subjects (twelve males, seventeen females, aged 17-19) in October 2013, sitting comfortably in front of a computer screen on which each image was shown for 6 or 12 seconds. It was forbidden to speak in order to avoid vibrations and the room was darkened.

We measured intensity and duration of fixation of each student with 6 or 12 seconds depending on the presentation of each stimulus (optic nerve, retina ...).

The test subjects were each given the task to identify certain cell structures. The total number of saccades and fixations were documented (software MathWorks, Inc., 
Natick, Massachusetts, U.S.).

The six stimuli during the first measurement series were spinal cord, motor neurons (figure 11), cerebellum (figure 5), purkinje cells, retina, and optic nerve (figure 4).

The two stimuli during the second measurement series were retina (400 x optically magnified, figure 6$)$ and the blind spot with the optic nerve (100 x optically magnified, figure 3 ).

Further eye-tracking recordings (third measurement series) were done in November 2014 on $2812^{\text {th }}$ grade students (11 female, 11 male; aged 17-19). The two different stimuli (retina, blood vessels in front of retina) were shown for $15 \mathrm{sec}$. each (e.g. figure 9).

The procedure of the study with high-speed, tower-mounted eye tracking included a pretest on interests in biological domains and self-assessment of microscopic competencies (questionnaire) [22], and a short interview following the scan path measurement.

\subsubsection{Comparison IWB/Conventional Microscopy}

Table 1. Contents of the courses with IWB and real microscopy, respectively

\begin{tabular}{|c|c|}
\hline $\begin{array}{c}\text { Courses with microscopy versus } \\
\text { IWB }\end{array}$ & $\begin{array}{c}\text { Courses without microscopy and } \\
\text { without IWB }\end{array}$ \\
\hline No 1: Seminar epithelium & No. 2 Seminar skeleton \\
\hline No. 3: Seminar muscle & No. 4: Food seminar \\
\hline No. 5: Digestion seminar & No. 6: Vitamins seminar \\
\hline No. 7: Eye seminar & No. 8: Senses seminar \\
\hline \multicolumn{2}{|l|}{ No. 9: Nerve seminar } \\
\hline No. 10: Blood seminar & No. 11: Heart seminar \\
\hline No. 12: Lung seminar & \\
\hline No 13: Kidney seminar & \\
\hline $\begin{array}{l}\text { No. 14: Gonads seminar } \\
\text { (not in 2012) }\end{array}$ & \\
\hline
\end{tabular}

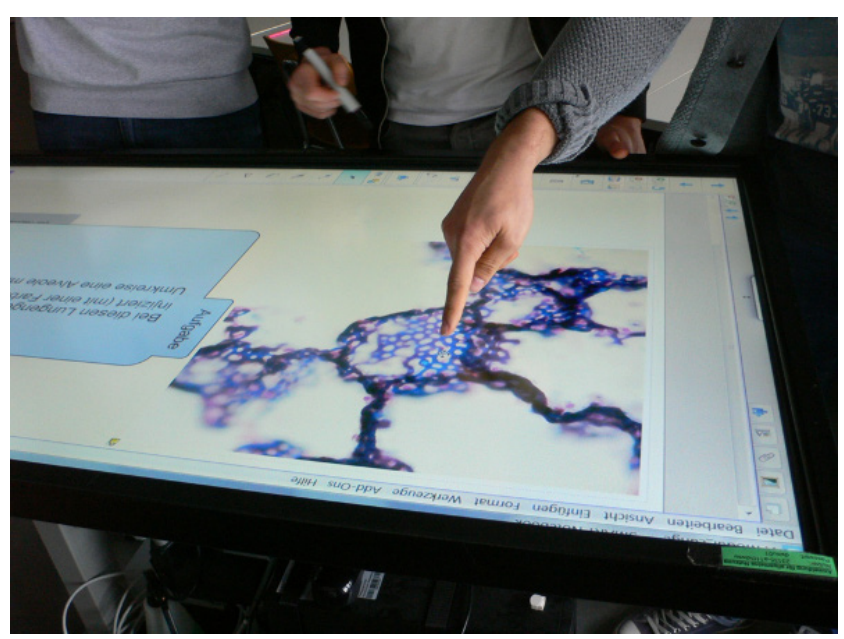

Figure 1. Interactive Whiteboard in collaborative learning situation

\section{Procedure of the Main Study (IWB/Microscopy)}

Total group of students:

Pretest on interest in biology

Pretest on interpretation of microscopic images

\section{5 seminars on human}

biological topics, each with

intrinsic motivation inventory (IMI)

and optionally
individual use of use of the
conventional $\quad$ IWB with the
specimen and $\quad$ support of a
microscopes tutor in small
Interim test on cellular interpretation
of microscopic images

6 seminars on further human

biological topics, each with

IMI, in part with FLOW-

questionnaires

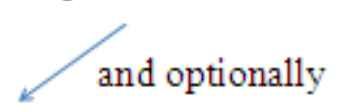

individual use of

conventional

specimen and

microscopes

use of the IWB

with the support of

a tutor in small

groups

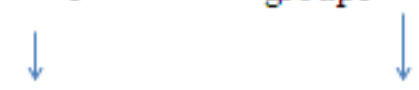

\section{Posttest on interests in biological domains \\ Posttest on interpretation of microscopic images}

Figure 2. Procedure of the main study (IWB/microscopy)

Human biological learning processes using digital, histological images are compared with the conventional use of the microscope. Microscopic images (lungs, kidney, skeleton, muscle, blood, heart, gonads, and nervous system) with varying magnification were integrated into IWB learning modules for pre-service student teachers. The modules focused on problem-based tasks that were discussed in small groups and accompanied by a tutor (see figure 10 as example for a module with images and tasks for epithelium). The processing of such modules took about 15 minutes. All students of one semester, studying to become teachers of biology, were test persons in both treatments. 
The instruments were questionnaires (short scale of intrinsic motivation [21], flow [20], and interpretation of microscopic images) and interviews.

The short questionnaire about intrinsic motivation (Ryan and Deci's IMI [21]) was employed every session. The flow short questionnaire [20] was employed several times. The flow questionnaire contained four items with 7-step scales, related to absorption through the task. Six items were related to the smooth of learning process. Three items should access the level of anxiety. According to Rheinberg [20], these 13 items were combined to "total flow" (Cronbach's Alpha: see table 4). Additional three items [20] measured the level of matching of the task to the participant's knowledge and skills (9-step scales). Additionally, tests were done to assess interest in the field of biology (pretest/posttest) [22]. Special knowledge tests connected with the concept of cells were done three times throughout the semester. Interviews with pre-service student teachers on the assessment of the IWB complemented the quantitative methods $(\mathrm{n}=9)$.

\section{Results}

\subsection{Examination of Eye Movements}

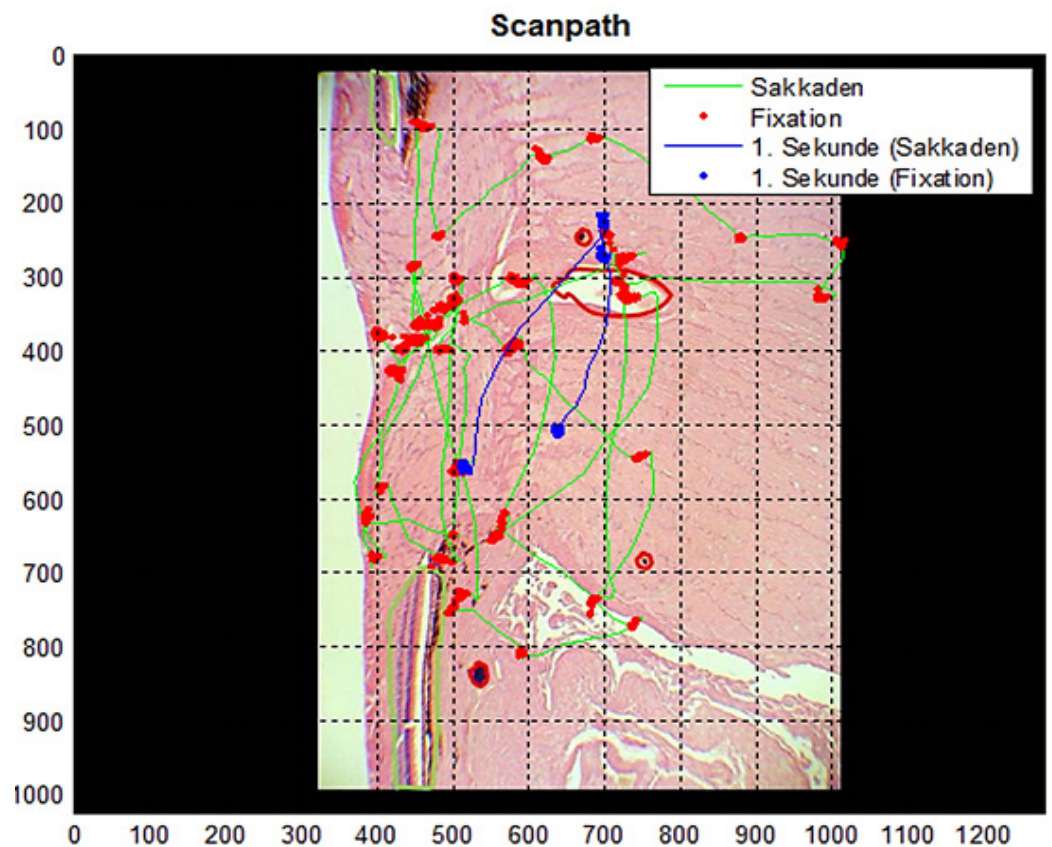

Figure 3. Example of a "scan path" when gazing at the optic nerve, the stimulus was presented 12 seconds long (measurement series 2 ), neither the retina nor the optic nerve were recognized by the test subject, despite the fact that the blind spot is part of the curriculum, $\mathrm{x} / \mathrm{y}$ pixel 1280 to 1024

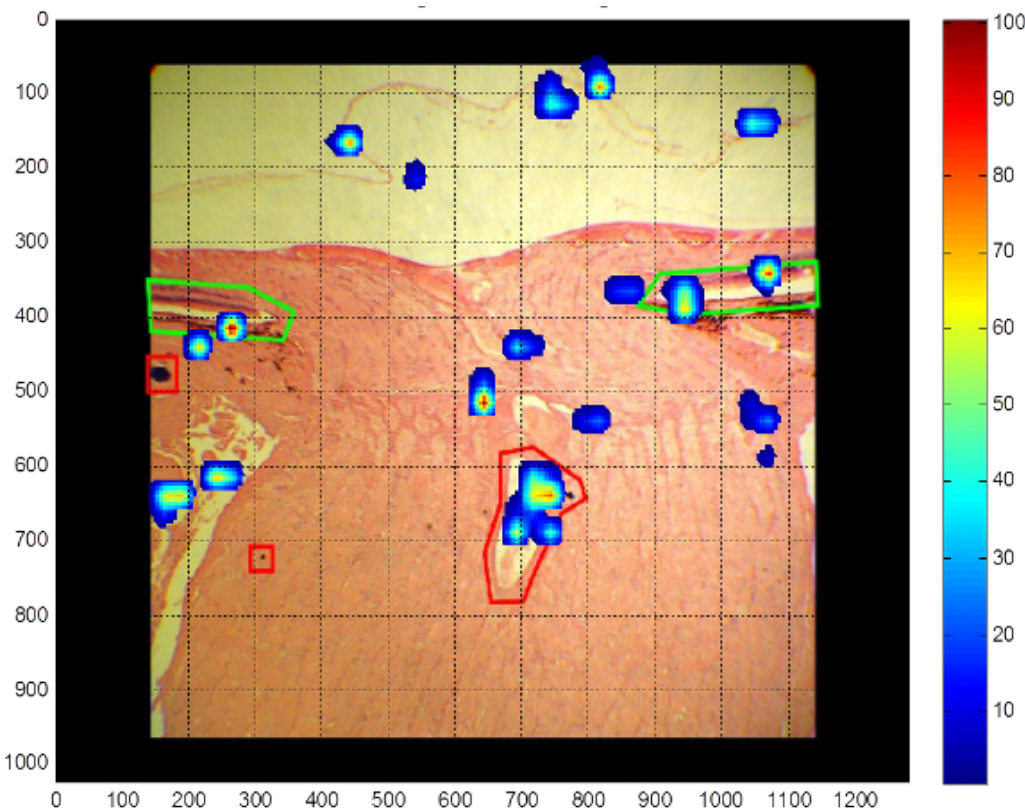

Figure 4. Example of a measured intensity of fixation when gazing at the histological image of the optic nerve, the stimulus was presented six seconds long, measurement series 1; the test person was classified as an expert 


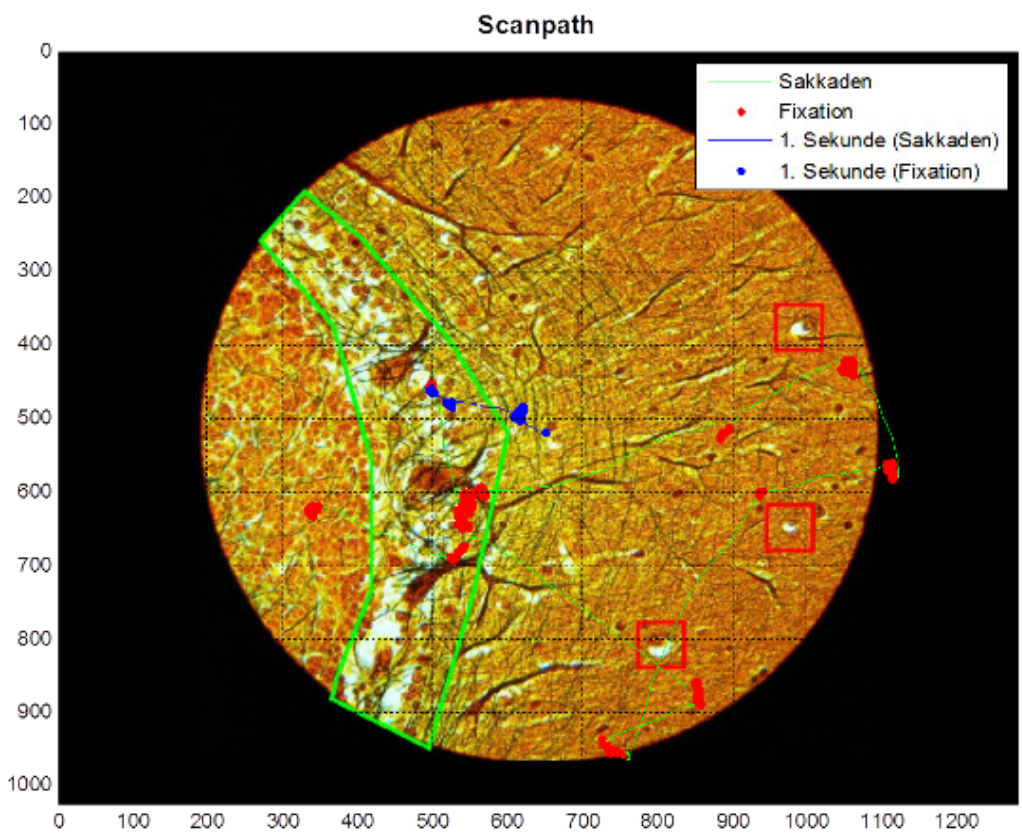

Figure 5. Example of a scan path of cerebellum and Purkinje cells for six seconds. The selected areas of particular interest to the issue are not visible for the student (fist measurement series)

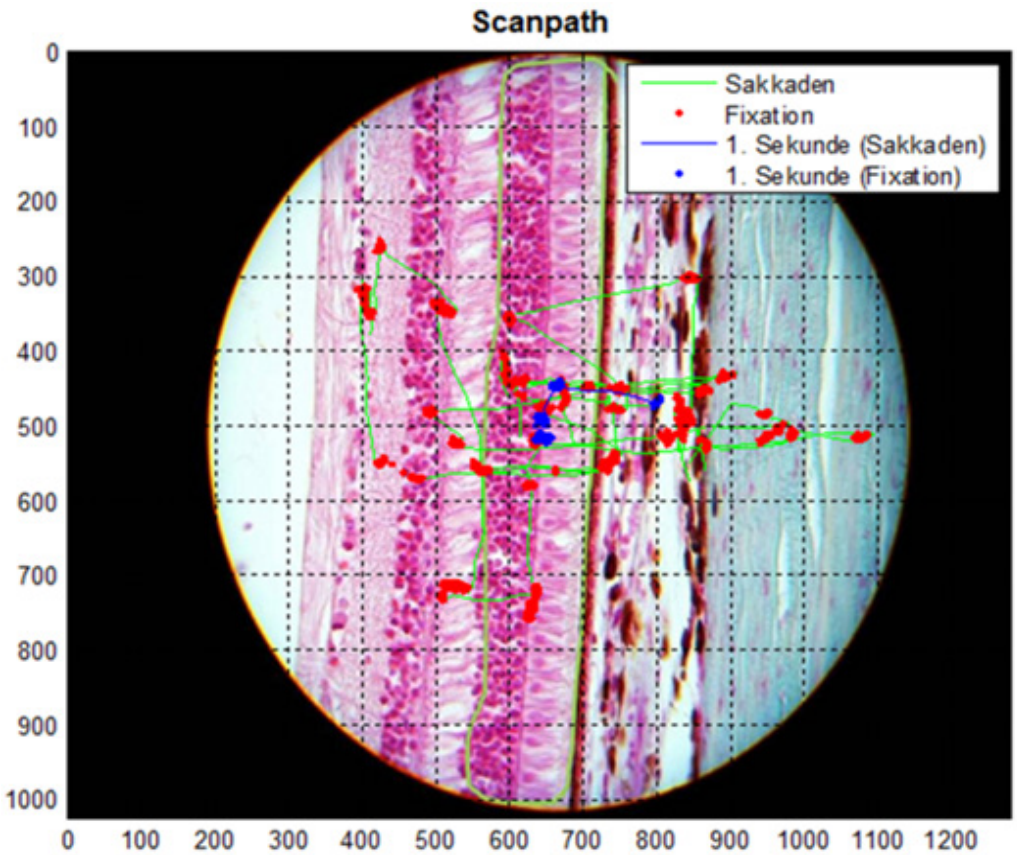

Figure 6. Stimulus retina, $400 \mathrm{x}$ optically magnified, example of a recorded "scan path" of the study of eye movements when gazing at the histological image for $12 \mathrm{sec}$., 35 saccades, searching for light sensory cells, x/y pixel 1280 to 1024. The test person was classified as an expert

Is it possible to measure the quality of microscopic competences? Within twelve seconds of observing the microscopic image (second measurement series, e.g. figure 6), around 32 fixations occurred among the 26 test subjects, regardless whether these had expert or novice status. The results of the interviews and self-assessment allowed the allocation of three categories of students' expertise. Two persons assigned these three levels of expertise to the students independently.

The arithmetic average of fixations for stimulus 1 (retina) is 32.8 (SD 3.74). The arithmetic average of fixations for stimulus 2 (blind spot) is at 34.03 (SD 3.67).

The total number of fixations and the expert status (three categories, determined in the interview and self-assessment) do not correlate; however, a larger proportion of fixations on the target cells occurred in test subjects with more knowledge. According to the model calculation (Mplus), there is a significant connection between expert status and the counted hits in the "Area of Interest” of stimulus 2 (ocular fundus with optic nerve). The number of hits in 
stimulus 1 and 2 are significantly different, not, however, the measured total number of saccades (t-Test) in stimulus 1 and stimulus 2 .

The qualitative analyses show: Only few subjects recognized the optic nerve and the retina segments in the image (stimulus 2 blind spot, see figures 3,4 ).

It is possible to distinguish among five strategies when searching for relevant structures in histological images of eyes and retina; some strategies led to the correct identification of light sensory cells.

1. Focusing on contrasts and dark areas (choroid, pigment epithelium)

2. Orientation on the side that is facing the light source (unsuccessful)

3. Repeated comparison of closely related structures (bipolar cells, light sensory cells)

4. Random search without concept (unsuccessful)

5. Scanning the whole image and rapid fixation of the target cell (most successful)

Table 2. Eye tracking stimuli without schema compared with schema and histological image

\begin{tabular}{|c|c|c|c|}
\hline $\begin{array}{c}\text { Students } \\
\text { (age 17-19) }\end{array}$ & $\begin{array}{l}\text { total number of } \\
\text { saccades and } \\
\text { fixations } \\
\text { (Mean) }\end{array}$ & $\begin{array}{l}\text { sought cells } \\
\text { were } \\
\text { identified }\end{array}$ & $\begin{array}{c}\text { additional } \\
\text { schema } \\
\text { was or } \\
\text { would be } \\
\text { valued }\end{array}$ \\
\hline $\begin{array}{c}\mathrm{n}=14 \text { Stimulus } 1: \\
\text { histological image } \\
\text { of retina cells }\end{array}$ & M 43.1 & $\begin{array}{c}n=13 \text { yes } \\
n=1 \text { no }\end{array}$ & $\begin{array}{c}\mathrm{n}=8 \text { yes } \\
\mathrm{n}=5 \text { no }\end{array}$ \\
\hline $\begin{array}{l}\mathrm{n}=14 \text { Stimulus 1: } \\
\text { histological image } \\
\text { and analog schema } \\
\text { of retina cells }\end{array}$ & M 46.9 & $\mathrm{n}=14$ yes & $\begin{array}{c}\mathrm{n}=12 \text { yes } \\
\mathrm{n}=1 \text { no }\end{array}$ \\
\hline $\begin{array}{c}\mathrm{n}=14 \\
\text { Stimulus 2: blood } \\
\text { vessels and retina }\end{array}$ & M 41.31 & $\begin{array}{l}\mathrm{n}=3 \text { yes } \\
\mathrm{n}=11 \text { no }\end{array}$ & $\begin{array}{c}\mathrm{n}=5 \text { yes } \\
\mathrm{n}=9 \text { no }\end{array}$ \\
\hline $\begin{array}{c}\mathrm{n}=14 \text { Stimulus } 2: \\
\text { blood vessels and } \\
\text { retina with } \\
\text { schemata of the } \\
\text { eye }\end{array}$ & M 51.92 & nobody & $\begin{array}{l}\mathrm{n}=7 \text { yes } \\
\mathrm{n}=6 \text { no }\end{array}$ \\
\hline $\begin{array}{l}\text { significant } \\
\text { correlations } \\
\text { (Spearman) } \\
\end{array}$ & \multicolumn{2}{|c|}{$\begin{array}{l}\text { with level of prior knowledge } \\
\text { and with measured fixation in } \\
\text { Area of Interest (AoI) }\end{array}$} & \\
\hline
\end{tabular}

\section{Comparison of Histological Images with/ without Analogous Schematic Drawing}

Additionally, a complementary study (third measurement series) measured how the total number of saccades and fixations increase by combining histological imaging and analogous schematic drawing (figure 9), compared to histological imaging without schematic drawing. The more difficult the images are because of movement between the image and the sketch increases, the more the number of fixations increases. Subjects that correctly identified the histological structures had significantly fewer fixations outside of the AoI. This is the case for both stimuli (retina, blood vessels in front of retina). Are these additional schemes helpful for interpretation of histological images? The data (Table 2) shows that in many cases they do not support interpretation of histological images despite the expectations of the students.

Table 3. Interest in fields of biology and microscopy competence $n=40$ summer semester 2014, Mean (SD) of summed indices. A total of 23 questionnaire items were evaluated (Cronbach's a $>0.890$ ) on an 8-step scale of agreement $(1=$ highest, $8=$ lowest $)$.

\begin{tabular}{|c|c|c|}
\hline & Pretest M (SD) & Posttest M (SD) \\
\hline Botany & $3.19(1.41)$ & $3.17(1.78)$ \\
\hline Zoology & $2.5(1.66)$ & $2.63(1.42)$ \\
\hline $\begin{array}{c}\text { Human } \\
\text { Biology }\end{array}$ & $2.15(1.66)$ & $2.09(1.42)$ \\
\hline $\begin{array}{c}\text { Molecular } \\
\text { Biology }\end{array}$ & $3.53(1.61)$ & $3.28(1.38)$ \\
\hline $\begin{array}{c}\text { Ecology \& } \\
\text { Environment }\end{array}$ & $2.79(1.61)$ & $2.67(1.45)$ \\
\hline $\begin{array}{c}\text { Field } \\
\text { Biology }\end{array}$ & $2.93(1.62)$ & $2.73(1.22)$ \\
\hline $\begin{array}{c}\text { Interest in } \\
\text { microscopy } \\
\text { with drawing }\end{array}$ & $5.1(1.87)$ & $4.63(2.18)$ \\
\hline $\begin{array}{c}\text { Interest in } \\
\text { microscopy without } \\
\text { drawing }\end{array}$ & $2.88(1.73)$ & $2.43(1.5)$ \\
\hline $\begin{array}{c}\text { Microscopy } \\
\text { competences }\end{array}$ & $3.55(1.73)$ & $2.7(1.07)$ \\
\hline
\end{tabular}

\subsection{Comparison IWB/Microscopy}

Pretests and posttests were used to assess interest in the field of biology. Table 3 shows interest in various domains of biology and self-perception of microscopy competence in 2014 as an example. The variable 'interest in human biology" correlates with the variable 'self-perception of competence in microscopy'. Interest in human biology is highly persistent. Interest in microscopic drawing, however, is low. These results are reproducible, recurring annually.

The second instrument was a short questionnaire about intrinsic motivation (Ryan and Deci's intrinsic motivation inventory IMI [21]) and was employed every session. The situational interest in the IWB or microscopy is not dependent on the time invested.

The third instrument was a special knowledge test. Competences in cellular interpretation of microscopic images (e.g. blood and retina) of both treatments increased significantly from the beginning to the middle, and again at the end of the seminar.

Additionally, the flow questionnaire [20] was employed several times. The flow experience overall reaches approximately the height of graffiti or computers games [20]. The IWB even provides students in a small group with a free choice of approach, which can lead to somewhat more flow than the use of conventional microscopes. 


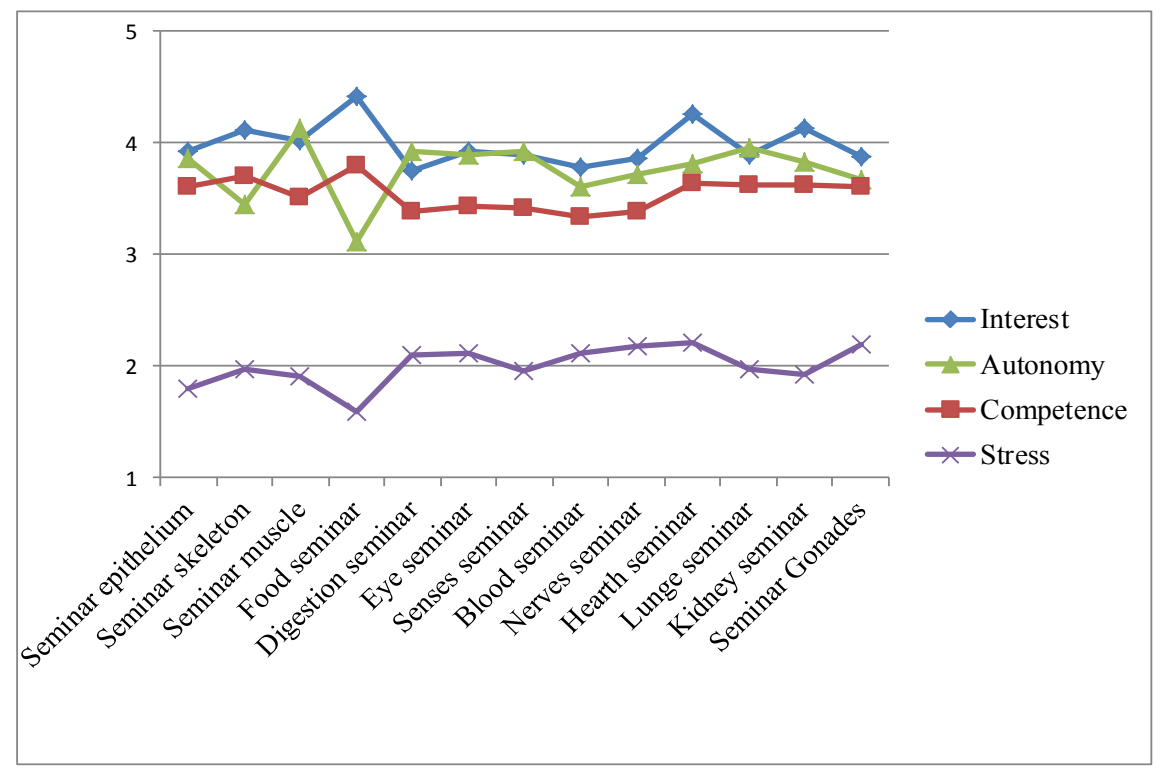

Figure 7. Analysis of the IMI questionnaires for seminars in course 2 winter semester 2013/14, the vertical scale of the graph shows mean response $(n=56)$ on a 5-point Likert Scale: 1 (no agreement) to 5 (full agreement).

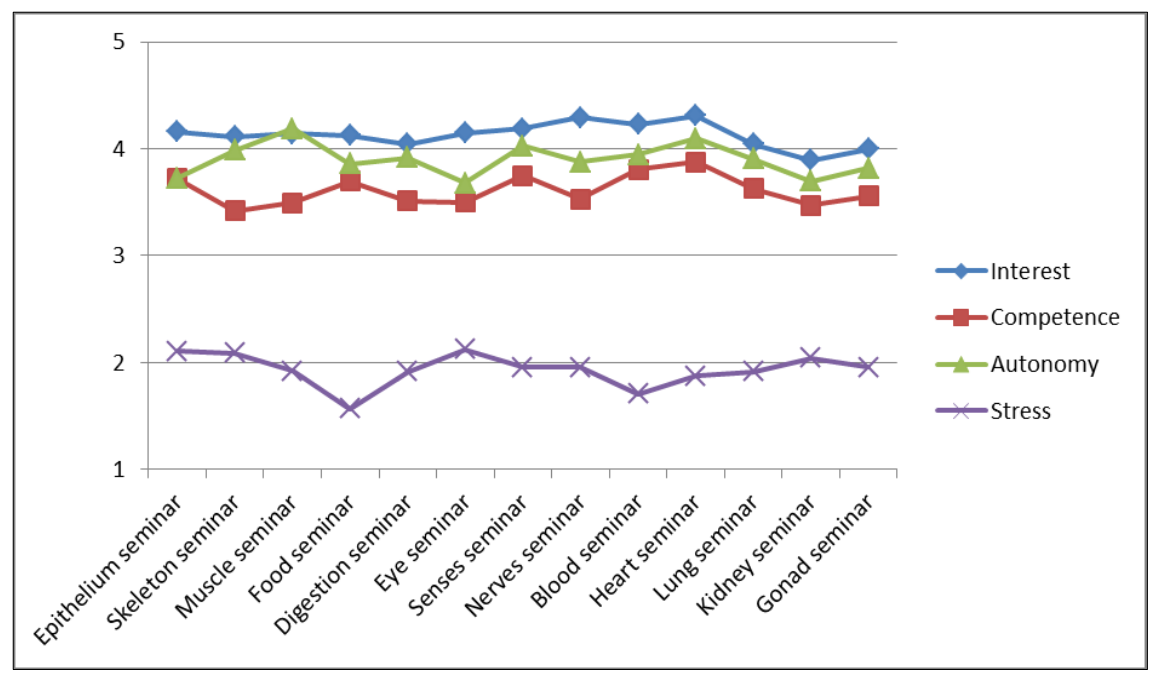

Figure 8. Analysis of the IMI questionnaires for seminars 1-13 in 2014; categories of situational interest, perceived competence, perceived autonomy of the learning process, and stress perception; the vertical scale of the graph shows mean response $(\mathrm{n}=56)$ on a 5-point Likert Scale: 1 (no agreement) to 5 (full agreement).

The positive values of interest and ratio of matching requirement of conventional microscopy using problem-based learning are not surpassed, however, by learning with digital images (figures 7,8 ).

In the guidelines-based interviews, the participants were asked to distinguish between pros and cons of the IWB and original microscopy. They reflected on their own experiences with the tools and instructional guidance.

Advantages of real microscopy were seen in the individual sense of achievement by immediate preparation of specimens, e.g. oral mucosa, blood smears, and brain specimens. It was mentioned as being an additional motivational factor that does not exist with respect to the IWB.

The problem-solving oriented learning process of the IWB was considered to be one of its advantages; answering a specific question helped to understand the shown images. The IWB also offers a more compact overview on the overall context and direct feedback supports comprehension of connections and functions of small tissues like marrow or cortex.

Negative aspects of the IWB are the immense amount of work as well as technical difficulties. 
Table 4. Measurement using the flow short scale [20] (13 Items, 7-step scales) and the additional item: „The current demands are ....too low ....exactly right ...too high for me (9-step scale)." *sign. difference: IWB/microscopy

\begin{tabular}{|c|c|c|c|c|c|}
\hline & $\begin{array}{c}\text { Mean (SD) } \\
\text { Matching with } \\
\text { demands } \\
\text { (9-step-scale) }\end{array}$ & $\begin{array}{c}\text { Total flow M } \\
\text { (SD) } \\
\text { (7-step scales) }\end{array}$ & $\begin{array}{c}\text { Absorption } \\
\alpha: .7324 \text { items } \\
\text { (7-step scales) } \\
\text { Mean (SD) }\end{array}$ & $\begin{array}{c}\text { Smooth process } \\
\alpha: .8526 \text { items } \\
\text { (7-step scales) } \\
\text { Mean (SD) }\end{array}$ & $\begin{array}{c}\text { Anxiety } \\
\alpha: .835 \\
3 \text { items } \\
\text { (7-step scales) } \\
\text { Mean (SD) }\end{array}$ \\
\hline \multicolumn{6}{|c|}{$2013 / 14$} \\
\hline $\begin{array}{l}\text { Microscope: blood } \\
\text { course } 1 \mathrm{n}=23\end{array}$ & $4.74(1.096)$ & $4.8(1.52)$ & $5.1(1.5)$ & $5.0(1.3)$ & $3.2(1.9)$ \\
\hline $\begin{array}{l}\text { Microscope: blood } \\
\text { course } 2 n=27\end{array}$ & $5.50(1.105)$ & $5.0(1.4)$ & $5.0(1.53)$ & $4.67(1.53)$ & $3.09(1.49)$ \\
\hline $\begin{array}{l}\text { Microscope: } \\
\text { kidney } n=17\end{array}$ & $5.50(0.437)$ & $4.81(1.39)$ & $4.92(1.51)^{*}$ & $4.73(1.3)$ & $4.4(1.85)$ \\
\hline IWB: kidney n=6 & $5.24(0.753)$ & $5.4(1.32)$ & $5.49(1.44)^{*}$ & $5.33(1.24)$ & $5.05(2.2)$ \\
\hline \multicolumn{6}{|c|}{2014} \\
\hline IWB: lung $n=14$ & $5.64(1.15)$ & $4.72(1.21)$ & $4.95(1.28)$ & $4.65(1.22)$ & $4.88(1.75)$ \\
\hline \multicolumn{6}{|c|}{$2014 / 15$} \\
\hline $\begin{array}{c}\text { IWB: eye } \\
\text { course } 1 \mathrm{n}=19\end{array}$ & $4.84(1.07)$ & $4.71(1.4)$ & $4.66(1.44)$ & $4.75(1.37)$ & $3.09(1.67)$ \\
\hline $\begin{array}{l}\text { Microscope: eye } \\
\text { course } 1 \mathrm{n}=12\end{array}$ & $5.25(0.96)$ & $4.77(1.54)$ & $4.88(1.51)$ & $4.54(1.53)$ & $3.3(1.91)$ \\
\hline
\end{tabular}

\section{Discussion}

The study tried to bring more into line our understanding of the difficulties in establishing microscopy with teaching strategies in cell biology.

In the sense of design based research, our process of searching and trial of new methods like eye tracking is still at the beginning. Independent and not independent variables are not known as whole.

Our first intention was to measure the quality of microscopic competences of learners.

\subsection{Discussion on the Subject of Eye Tracking}

Roa-Peña et al. [25] argued in 2010:

"Overall, navigation patterns in virtual microscopy have been recently studied, and the few reported studies use very complicated interfaces such as eye trackers, which may bias the observed patterns". These articles [25, 26] discussed and compared pathologists with high degree of expertise.

"First examination is carried out at the lower magnification (panoramic) in order to locate relevant information in terms of a spatial organization of the histological sample (scanning), while the second and further examination is conducted for analysis of the slide contents which implies changing the magnification (zoom)."

This learned strategy has been observed in multiple studies of pathologist's navigation patterns in virtual microscopy in which it has been possible to determine the existence of these two phases.

The focus of our study is teaching microscopy at school. This seems to be another level of expertise.

Digital histological images were used for the eye-tracking study, despite the technical possibilities of tower-mounted high quality eye-tracking recordings. The results should be comparable to conventional microscopy according to studies of Furness [8] - see above. Our histological images had no pathological entity.

The available variables are interest in biology (questionnaire), number and duration of saccades and fixation (eye tracking), expert status (evaluated/judged by different persons); results of interviews were taken into account. Following review of the scales, the following manifest variables of the main survey were considered for the latent variable "self-perception": Interest in human biology, self-perception of microscopy competences, and enjoyment of viewing microscopic images (eight-step Likert scales, Cronbach's Alpha $>0.95$ ).

The results of the interviews and self-assessment allowed the allocation of three categories of students' expertise. Two persons assigned these three levels of expertise to the students independently.

According to the model calculation (Mplus), there is a significant connection between expert status and the counted hits in the „Area of Interest" of the demanding stimulus "ocular fundus with optic nerve" (second measurement series, stimulus no. 2). This hit ratio, however, was hardly dependent on the self-perception of the subject group (latent variable: self-perception). Stimulus 2 (optic nerve) was more difficult, (magnification up to 100x) than stimulus 1 "layers of the retina" (up to 400x, cellular level), depending on the level of magnification. Stimulus 1 looks more like the cellular schema than stimulus 2 (second measurement series). The number of hits in stimulus 1 and 2 are significantly different, but not the measured total number of saccades (t-Test) in stimulus 1 and stimulus 2 .

Most of the variance of the variable hints in the area of interest is due to the variable expert status. Hits in the "Areas 
of Interest" are good indicators for expertise; total numbers of saccades are not enough on their own.

The student experts in our study adopt a similar strategy to studies of Roa-Pena [25] - see above, "i.e., a general search strategy and selection of areas". The pathologists could change magnification during exploration of histological images [25]. Our students could not do this during eye tracking. "So far our observations indicate what has been described in the literature, that is to say, navigation is composed of two complementary strategies: scanning and magnification." [25] We have taken this aspect into account by using two histological images of different magnification of each tissue. We can confirm that the magnification level plays a role in recognizing.

For IWB technology it is important for us to make it possible to change the magnification while recognizing histological images.

The eye movement analysis reveals obstacles to the comprehension of cellular configurations, for example, disorientation between bipolar cells and light sensory cells or between muscles and optic nerves of the eye. If microscopic slides of histological images have other colors than images seen earlier, students seem to become confused. The qualitative examination of the eye movements gives evidence to the advantages of problem-orientated observation of images by high school students, as discussed in the interviews after the eye tracking. "Some virtual slides were little-explored because relevant information was easily available." According to studies of Roa-Peña et al. [25] this could be relevant for school students too.

Schemata alone are not sufficient to come to decisions about cells and histological structures. This could be seen very clearly in the results of the eye tracking study with the comparison of histological images without schemata to histological images with schemata (third measurement series). It depends on the level of the research task and the prior knowledge of the learner whether a schematic image as instructional guidance seems to be helpful. Whether a schematic drawing as instructional support is considered to be helpful or distracting seems to be dependent on the level of difficulty of the problem. When the tissue of the image is quite familiar, as is the case with retina layers, around half of the subjects' state that they could forgo the sketch. The schematic drawing of the eye with blood vessels (see figure 9) was less helpful for searching for blood vessels in front of and behind the retina. The number of subjects in qualitative eye-tracking are, however, still low. The results support, nonetheless, the assumption of Expertise Reversal Effect [10, 14] (see table 2).

Students overestimated the size of neurons and sensory cells and underestimated their number. Consequently, they had difficulties detecting these in histological images or were not able to detect them at all because they had not had enough practice doing this. Practice seems to be indispensable for "learning to see". To grasp the "Nature of Science," it seems important that the students understand the process of creating a schema by abstracting and reconstructing, beginning with the histological image. Textbook-schemata often show only individual cells. Through microscopy, students are supposed to more easily understand the connections between structure and function than through abstract representation only.

Which didactic methods could be helpful? Spoken language could influence the measurements as well as the thinking. In order to avoid vibrations, it was forbidden to speak during electronic recording of scan path. We cannot make any statements about the influence of a direct didactic or linguistic "trigger" during image viewing, however. This should be the subject of our future research with another eye tracker.

\subsection{Discussion on the Subject of IWB}

As seen in table 3, there is considerable improvement of interest in microscopy over one semester and in self-assessment of microscopy competences. Interest in microscopic drawing was increasing and is not as low as before. The increase in real knowledge and correct Interpretation of histological images (blood, retina) is significant. In our opinion this is due to the problem orientation in both treatments (with IWB, with real microscopy). The motivation in the course of the semester is proof that interest could be triggered (see Figure 7 and 8).

Pre-service student teachers reflected on advantages and disadvantages of the IWB during the Interviews in a differentiated manner. The possibilities of enlarging the images through touch, however, and of labeling or sketching were helpful. In our opinion, the importance of conventional microscopy is based on the opportunity to experiment individually [24]. Digital histological images can be a valuable supplement but cannot substitute original microscopy.

It is an immense amount of work to design interactive material. At the same time, learning material can often be used when different levels of learners are considered.

Instructional designers, however, should consider the learners' level of expertise and their cognitive load when applying design principles [23]. When initial technical problems have been overcome, digital images can achieve similar effects to conventional images, in a collaborative approach. Combinations of text and image using histological images may be useful, as seen in the interviews. The positive values of interest and ratio of matching requirement of conventional microscopy using problem-based learning are not surpassed, however, by learning with digital images (figures 7,8), as seen in the measurement of flow, appropriate requirement, and motivation.

Different from [13], we consider the IWB to be a tool through which development and communication can take place in the process of acquiring knowledge and not as a main tool for frontal presentation by the teacher. This is why we do not use the IWB as a vertical board but rather as a 
horizontal table with touch functions (figure 1, 10). Sieve [13] refers to the importance and the limits of the software of the IWB in connection with didactic potentials in lessons. This SMART-Software deficiency prevented us from integrating high quality microscopic live images in the lesson modules. Instead, conservative histologic images had to be integrated.

In conclusion, it is obvious that qualified feedback and clear research questions concerning conventional and digital microscopy appear to be beneficial to learning. Combinations of text and histological image are useful. Schemata alone are not sufficient to recognize cells and histological structures. Didactic preparation and consideration of prior knowledge are essential to reduce students' widespread reluctance concerning microscopy.

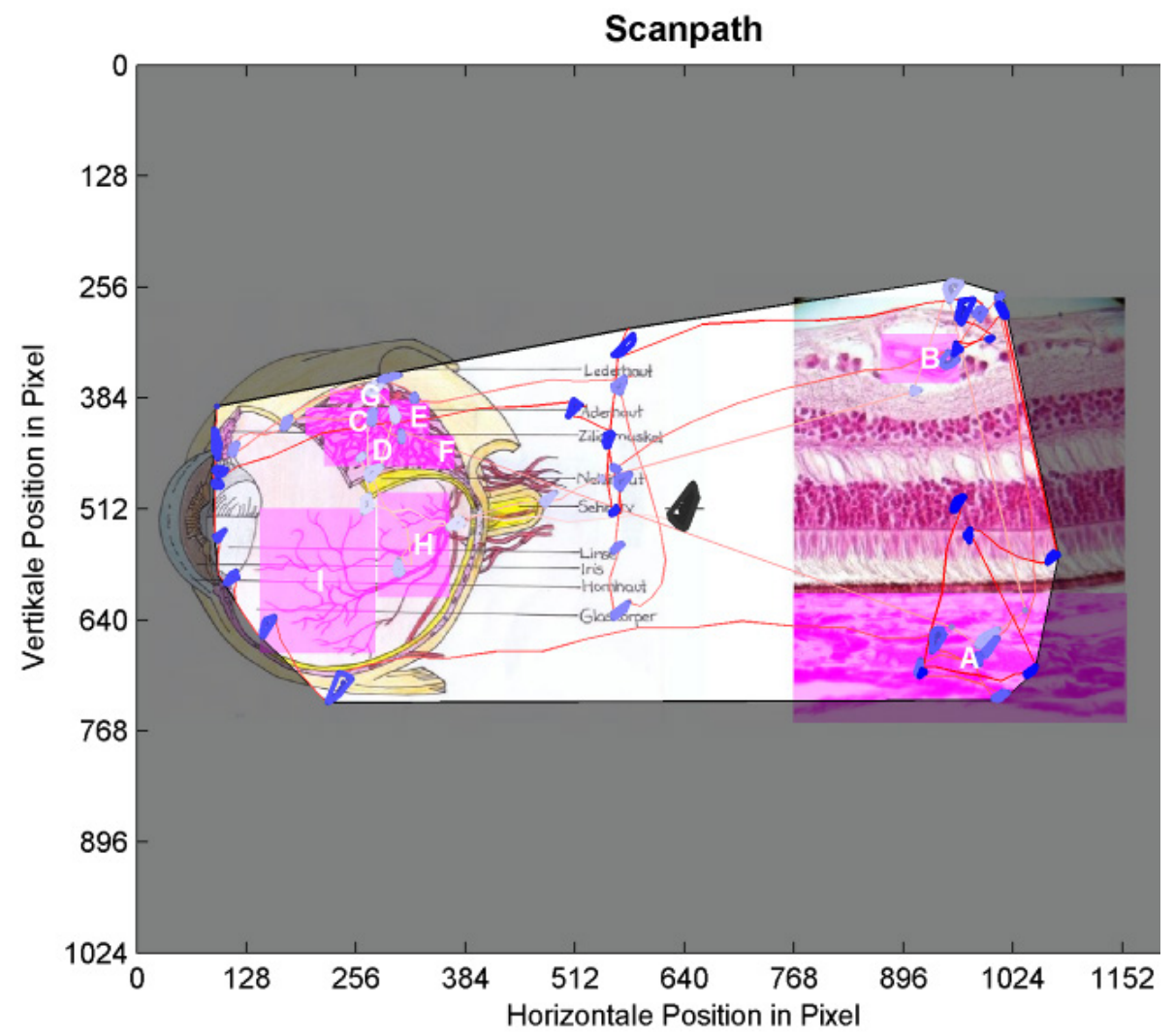

Figure 9. Example of a recorded "scan path" when looking at a histological image of the retina and a schema of the retina ( 15 sec.) (third measurement series)

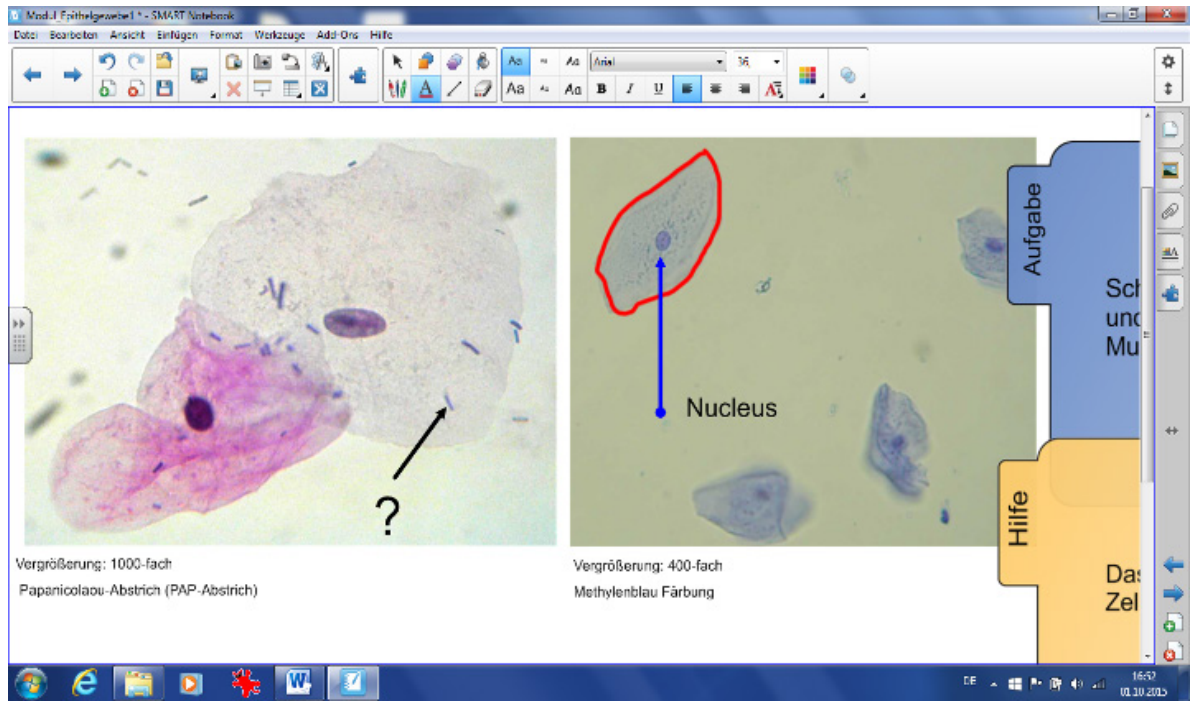

Figure 10. Example of learning modules for IWB about epithelium, screenshot 


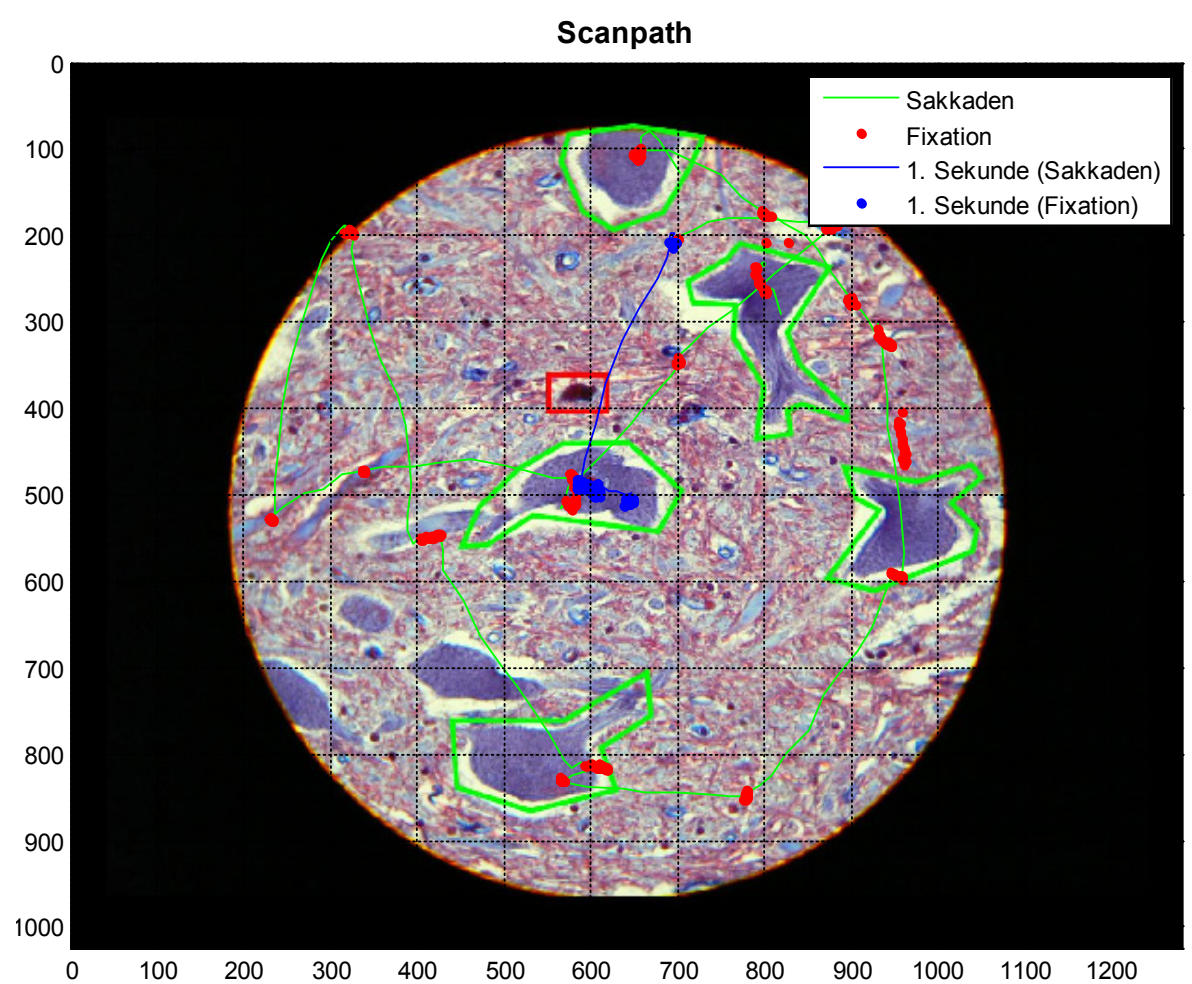

Figure 11. First measurement series, scan path, student is searching motoneurons, 6 seconds

\section{Acknowledgements}

We thank Uwe Ilg and David J. Mack for the opportunity to use the Eye Tracking system in Tuebingen and, most of all, for their wonderful cooperation.

\section{REFERENCES}

[1] St.-P. Ballstaedt. Wissensvermittlung. Die Gestaltung von Lernmaterial, Beltz, Psychologie Verlags Union, Weinheim, 1997.

[2] K. L. Alesandrini. Pictures and adult learning. Instructional Science, 13, Amsterdam, pp. 63-77, 1984.

[3] L. Jäkel. Working with the microscope as a problem solving process. In C. Bruguière, A. Tiberghien \& P. Clément (Eds.), E-Book Proceedings of the ESERA 2011 Conference: Science learning and Citizenship. Part: Pre-service science teacher education, co-ed. D. Psillos \& R. M. Sperandeo, Lyon, France, ESERA, 2012.

[4] M. Merk, R. Knuechel, A. Perez-Bouza. Web-based virtual microscopy at the RWTH Aachen University: Didactic concept, methods and analysis of acceptance by the students, Annals of Anatomy, 192, 6, 20. December, pp. 383-387, 2010.

[5] J. Amano, A. Yamanaka, S. Kawakami. Advanced activities using microscopes at a science museum to strongly promote children's interest in science. ESERA international conference, Nikosia September 2013.
[6] A. Korres, S. Ribeiro, P. dos Santos, et al. Didactic and workshop experience in microscopy for high school and college students. In A. Méndez-Vilas (Ed.), Microscopy: advances in scientific research and education, 2, 6, pp. 1137-1144, Badajoz, Formatex, 2014.

[7] D. Romer, \& S. Suster. Use of virtual microscopy for didactic live-audience presentation in anatomic pathology, Ann. Diagn. Pathol., 7,1, pp. 67-72, 2003.

[8] P. Furness. A randomized controlled trial of the diagnostic accuracy of internet-based telepathology compared with conventional microscopy. Histopathology, 50, 2, pp. 266-273, 2007.

[9] R. E. Mayer. Cognitive theory of multimedia learning. In R. E. Mayer (Ed.), The Cambridge Handbook of Multimedia Learning pp.31-48, Cambridge: University Press, 2005.

[10] J. Sweller, van Merrienboer, \& F. Paas. Cognitive architecture and instructional design. Educational Psychology Review, 10, pp. 251-296, 1998.

[11] R. Q. Quiroga, C. Pedreira. How do we see art: an eye-tracker study. Frontiers in Human Neuroscience, 5, 98, pp.1-9, 2011.

[12] B. Brucker, J. Edelmann, R. Brömme, \& P. Gerjets. The proximity of the hands to the objects influences learning on multi-touch devices: Touch pictures, but don't touch words! Proceedings of EARLI Special Interest Groups Instructional Design \& Learning and Instruction with Computers: Seeing eye to eye: New approaches to studying and designing social aspects of learning and instruction, Rotterdam, The Netherlands, 2014.

[13] B. F. Sieve. Interaktive Tafeln im naturwissenschaftlichen Unterricht. Entwicklung und Evaluation einer Fortbildungsmaßnahme für Chemielehrkräfte, Wiesbaden, Springer Spektrum, 2015. 
[14] S. Kalyuga, P. Ayres, P. Chandler, \& J. Sweller. The expertise reversal effect, Educational Psychologist, 38, pp. 23- 31, 2003.

[15] R. Moreno \& R. Mayer. Interactive multimodal learning environments. Educational Psychology Review. Springer, 2007.

[16] A. 1. Yarbus. Eye movements and vision. New York: Plenum Press, 1967.

[17] D. J. Mack, \& U. J. Ilg. The effects of video game play on the characteristics of saccadic eye movements, Vision Res, 102, 26-32, 2014.

[18] C. A. Banzhaf, H. Lund, K. Zarchi, H. F. Lorentzen, G. Argenziano, \& G. B. E. Jemec. Recognizing Melanoma - Eye Movement Patterns in Dermoscopy - Differences between novices and those experienced in dermoscopy, 17. European Conference on Eye Movements, 11-16.August, Lund, Sweden, 2013.

[19] T. Jaarsma, H. Jarodzka, M. Nap, J.J.G. Van Merrienboer, \& H.P.A. Boshuizen. Expertise Development under the Microscope. 17. European Conference on Eye Movements, 11-16. August, Lund, Sweden, 2013.

[20] F. Rheinberg, R. Vollmeyer, \& S. Engeser. Die Erfassung des Flow-Erlebens, In J. Stiensmeier-Pelster \& F. Rheinberg, Hrsg., Diagnostik von Motivation und Selbstkonzept, Göttingen, Hogrefe, 261-279, 2003.
[21] E. L. Deci, R. M. Ryan. Intrinsic Motivation Inventory, 2003 Online available (retrieved Nov 19th 2009)

[22] http://www.psych.rocherster.edu/SDT/measures/intrins.html.

[23] L. Jäkel. (2014). Interest and Learning in Botanics, as Influenced by Teaching Contexts, In C.P. Constantinou, N. Papadouris \& Hadjigeorgius (Eds.), E-Book Proceedings of the ESERA 2013 Conference: Science Education Research For Evidence-based Teaching and Coherence in Learning. Part 13, co-ed. L. Avraamidou \& M. Michelini, pp.12, Nicosia, Cyprus, ESERA, 2014.

[24] G. D. Rey, \& F. Buchwald. The expertise reversal effect: Cognitive load and motivational explanations. Journal of Experimental Psychology, 17, 1, pp. 33-48, 2011.

[25] U. Schiefele, A. Krapp, \& I. Schreyer. Meta-Analysis of the Relationship between Interest and Academic Achievement. Zeitschrift für Entwicklungspsychologie und Pädagogische Psychologie, 25, 120-148, 1993.

[26] L. Roa-Peña, F. Gómez, \& E. Romero. An experimental study of pathologist's navigation patterns in virtual microscopy. Diagnostic Pathology. 5, 71, 2010.

[27] E.A. Krupinski, A. Tillack, L. Richter, J.T. Henderson, A.K. Bhattacharyya, K.M. Scott, A.R. Graham, M.R. Descour, J.R. Davis, \& R.S. Weinstein. Eye-movement study and human performance using tele pathology virtual slides: implications for medical education and differences with experience. Hum Pathol. 2006 12, 37, pp 1543-1556, 2006. 